\title{
ENTRE LA IMAGEN Y EL SILENCIO \\ La palabra escindida en Caleidoscopio de Gustavo Montes
}

\author{
Mabel Brizuela \\ Profesora de Literatura Española Contemporánea. Universidad Nacional de Córdoba \\ (Argentina)
}

\section{Resumen}

El presente trabajo propone un análisis e interpretación de Caleidoscopio de Gustavo Montes. Una fuerte articulación se revela a partir de las tensiones entre pantalla y escenario, entre palabra e imagen, cuyos mecanismos y estrategias nos permiten plantear una singular expresión dramática.

\section{Palabras clave}

Caleidoscopio - pantalla/escenario - palabra/ imagen - tensiones - articulación estrategias - expresión dramática

\section{Abstract}

The present paper attempts at presenting an analysis and interpretation in Gustavo Montes’s Caleidoscopio. A strong articulation is revealed by the tensions between the screen and the stage, the word and the image, whose mechanisms and strategies allow us a singular dramatic expression. 


\section{Key words}

Caleidoscopio - screen/stage - word/image - tensions - articulation strategies - dramatic expression

\section{Introducción}

Como "un teatro intenso" define el primero de sus diez mandamientos al Teatro Hurgente que "se escribe con H como expresión de búsqueda de lo soterrado, de lo que permanece silencioso, mudo. Como expresión del silencio. La H también como irreverencia”, tal como aclara la segunda Revelación adicional a esos mandamientos. Las obras del Teatro Hurgente se representan en el Teatro Janagah de Madrid, "un espacio audiovisual que es un lugar de encuentro con un espíritu opuesto al de las salas comerciales” según señala Gustavo López (2004) director, y uno de los responsables de este colectivo, juntamente con Gustavo Montes, autor, ("VI Premio de Teatro Martín Recuerda") para quien el Teatro Hurgente es un teatro intenso “... que busca trasladarlo /al espectador/ a la verdad dramática", con piezas que tienen "un intento de exploración creativa, de trascender la fugacidad de la noticia, de la anécdota, de crear una verdadera obra literaria” (2005).

En el Prólogo de la -hasta ahora- primera Trilogía de Teatro Hurgente, Off familias (2005) Gustavo Montes, que se siente deudor de autores como Beckett, Pinter, Shepard, Sanchis Sinisterra, y nuestro Mauricio Kartun, señala que los diez mandamientos: Nacieron motivados por una doble necesidad. Por un lado, la necesidad de tener un armazón poético con el que sostener la estética y la ética de nuestras historias desde su concepción como texto hasta su puesta en escena. Por otro lado, la necesidad funcional pero no menos importante de adaptar nuestro trabajo a un espacio de dieciséis metros cuadrados: el escenario del Janagah. Toda poética, desde Aristóteles, pasando por la Carta a los Pisones de Horacio, El Arte Nuevo de hacer comedias de Lope, el Prólogo a Cromwell de Victor Hugo, el Naturalismo de Zola, los manifiestos surrealistas de André Breton y otros muchos 
manifiestos hasta llegar al último Dogma cinematográfico, genera una forma de hacer, una forma de contar y de ver la vida. Y en ese momento, en cuanto la vida se cuenta, se toma partido. De ahí que definamos al Teatro Hurgente, pese a no ser esencialmente mimético, como un teatro político en nada ajeno a lo que ocurre en la realidad...

\section{Objetivos}

El presente trabajo tiene por objetivo el análisis e interpretación de la funcionalidad textual y escénica de la pantalla como signo central en Caleidoscopio de Gustavo Montes. Es producto de una reflexión estimulada por estas palabras de P. Pavis (2001):

Este tipo de enfrentamiento simbólico entre la palabra individual y los medios de comunicación es frecuente en el teatro actual. Tiene que ver con los medios de comunicación, en particular audiovisuales, y la escritura dramática, artesanal, individual, que con frecuencia está acorralada, a la defensiva y, en ocasiones... dispuesta a pasar al contraataque.

\section{Metodología}

El modelo de análisis se conforma desde una perspectiva semiótica, teniendo en cuenta las unidades sintácticas, con su dimensión estructural y de construcción como también los valores semánticos que pueden encontrarse en ellas y muy especialmente las relaciones pragmáticas que el texto y sus unidades mantiene con referentes extratextuales y con los sujetos de la comunicación. Se consideran los aportes metodológicos de C. Bobes Naves (1997). 


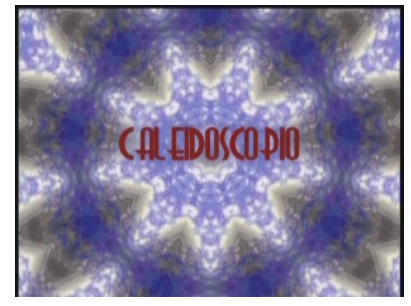

Gustavo Montes ha escrito, entre otras obras, Dos obreros, Ojos y El bus reunidos en la trilogía Off Familia's (2005), Ulises (2005), Caleidoscopio (2005), En negro (2005), Algo sigue su curso (2006), todas ellas representadas en el espacio del Teatro Janagah de Madrid y dirigidas por Gustavo González López. La Nota de Prensa (2006) de Caleidoscopio (2006, finalista del "IV Premio Madrid Sur para Textos Teatrales") presenta su síntesis argumental y espectacular:

Una distancia transoceánica, la existente entre Lima y Madrid, separa a la pareja protagonista de la obra, una actriz peruana y su ex amante, un cameraman que se ha trasladado a Madrid. A través de la convergencia de códigos audiovisuales y escénicos, la historia plantea el conflicto entre dos mundos: la palabra y la imagen, el amor y la incapacidad para vivirlo.

El título, como orientador de lectura, anuncia la fractura del tiempo y el espacio y la intervención del azar, que mueve las piezas de este caleidoscopio uniendo o separando mundos y personajes de modo antojadizo. Por su parte, la acotación escénica inicial con un carácter, más que referencial, poético y metateatral, es la expresión, en primera persona, de un sujeto que imagina un espacio y que anticipa un texto no convencional:

Imagino un espacio completamente blanco, de tal modo que la vista confunde suelo y fondo: un espacio que no es espacio, sino ausencia de espacio. Una gran pantalla en el centro divide el escenario en dos mitades (quizás no lo divide, quizás une ambas mitades). A la izquierda tendremos el mundo de LÚA (el mundo de la 
palabra) y a la derecha el mundo de MIGUEL (el mundo de la imagen). Imagino un decorado austero, blanco también, y polivalente: lo que parece un colchón sobre el suelo se convierte en una mesa en otro momento. Sin embargo, imagino el vestuario de los personajes completamente naturalista y reales determinados objetos: cámaras de vídeo, un aparato de televisión, una silla alta, una taza de té...

Este no es un texto convencional (no es una virtud, sino simple constatación). Quizás convenga aclarar, por tanto, que la acción transcurre en el escenario y proyectada en la pantalla central. La primera aparecerá bajo la leyenda “ESCENARIO”. La segunda bajo la leyenda “PANTALLA”. En este último caso la acción se desarrollará en espacios reales. Obviamente, cuando la acción es simultánea, la leyenda será “PANTALLA/ESCENARIO” y en la pantalla veremos preferentemente planos cercanos de los personajes en el escenario: gestos, detalles, matices, emociones...

Conceptos como interdisciplinariedad, intertextualidad, fragmentación están presentes de una u otra manera en este texto dramático.

El espacio se define por su ausencia, con un decorado austero donde sólo se destaca la "gran pantalla en el centro” que divide (¿o une?) el escenario y que proyecta acciones desarrolladas en “espacios reales”. El espacio escenográfico, patente ${ }^{1}$, limita al extremo su referencialidad, en tanto el espacio virtual de la pantalla, latente, la recupera a través de una imagen siempre mediatizada.

En una compleja estructura de caja china, con ilimitados reflejos y refracciones, se suceden 27 secuencias, divididas todas por “oscuro”, de acuerdo a una segmentación que toma como signo recurrente la luz/oscuridad para diferenciar las secuencias. En su mayoría alternan los dos espacios geográficos, Lima y Madrid, donde se ubica a Lúa y Miguel, respectivamente, separados por un océano y con una “desesperada necesidad de diálogo” (2006). Esta alternancia (escenario/pantalla,

\footnotetext{
${ }^{1}$ En un sentido general se llama espacio patente a todo lo que se ve en el ámbito del espacio escénico o escenario concreto donde se realiza la puesta, en tanto el espacio latente es aquel que no se ve representado en escena pero que los espectadores saben que existe, por los diálogos de los personajes. (Bobes, 1997, Brizuela, 2000, 28-30) En este caso, se considera espacio latente al de la pantalla por su virtualidad, por su falta de concretización escénica.
} 
palabra/imagen), fragmenta constantemente la diégesis en una intrincada red de signos que se entrecruzan y entremezclan. Nada está completo, todo aparece aquí cortado, interrumpido, fraccionado: el escenario, la pantalla, la palabra y la imagen. No hay un hilo de Ariadna que nos oriente, sino múltiples bifurcaciones, innumerables cristalitos de colores que funden en pantalla y escenario, la imagen reveladora del título. Así se presentan en la secuencia 1:

\section{PANTALLA/ESCENARIO}

(... Sobre la pantalla imágenes de un caleidoscopio. Las imágenes se proyectan al mismo tiempo sobre el escenario blanco: una pantalla dentro de la otra. En ambas, los cristalitos azules, rojos, blancos del caleidoscopio componen cambiantes figuras geométricas. Sobreimpresionado aparece el título de la obra.

\section{La imagen se repite en la secuencia 11:}

\section{PANTALLA}

(En la oscuridad del escenario, la pantalla muestra imágenes de un caleidoscopio: cristalitos de colores que imponen sus formas y colores cambiantes).

\section{PANTALLA/ESCENARIO}

(Los cristalitos de colores de la pantalla se han extendido ahora sobre el escenario, proyectándose también sobre el cuerpo desnudo de MIGUEL. Se encuentra solo, tirado en el suelo en una postura fetal. Mira a través de un caleidoscopio. De tanto en tanto, coincidiendo con el movimiento de los cristalitos en la PANTALLA, lo hace girar con la mano. El fondo azul permanece en la pantalla de la televisión).

En la secuencia 18, a través de la cámara, Lúa regala a Miguel un caleidoscopio:

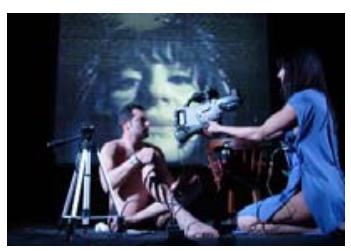




\section{PANTALLA}

$\cdots$

(Se limpia los labios con una servilleta y saca de debajo de la mesa un paquetito envuelto en papel de colores. Lo coloca sobre la mesa, frente a la cámara).

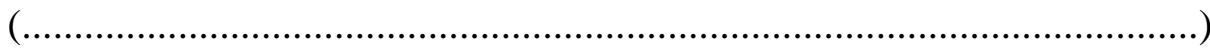

(Lo desenvuelve con la misma emoción que si lo hiciera el homenajeado. Entre sus manos aparece un caleidoscopio, el mismo que hemos visto anteriormente en las manos de Miguel).

¿Te acuerdas? Lo estuviste mirando en el mercadillo de la Plaza de la Independencia. No lo compraste porque te pareció caro,...

La misma imagen cierra la obra en la sec. 27: (Sobre el escenario, imágenes de un caleidoscopio. Cristalitos azules, blancos, rojos que componen cambiantes figuras geométricas).

La imagen de los cristalitos del caleidoscopio, diseminados sobre el escenario, funciona como el eje anafórico de la pieza (Serpieri, 1977, 106-109) que, en la secuencia 11, se carga de sentido al trascender la mera reiteración lumínica para convertirse en efecto de una acción: es el propio Miguel quien manipula el caleidoscopio y forma con él las figuras. Del mismo modo, en ese espacio desnudo, des-habitado por los personajes, se diseminan también los retazos de una historia de engaños y frustraciones, que la palabra es incapaz de revelar. La pantalla destaca gestos, movimientos y silencios que se imponen como tema y sustancia de una obra esencialmente intertextual, en un sentido general, de cruce de discursos y de textos, donde las relaciones, los sentimientos y los enigmas de los personajes se verbalizan a través de sus palabras y se manifiestan mediante las proyecciones que invaden la escena, a la vez que articulan y desarticulan el entramado dramático. No hay apenas acción, no hay historia. Trozos y retazos de réplicas e imágenes, piezas aisladas de un caleidoscopio cuyas figuras los espectadores deben formar. Se trata, de "un texto que pone en crisis la palabra, que la cercena y la enfrenta a la contundencia de la imagen y del silencio" (Brizuela, 2007). 
El discurso de los personajes, deshilvanado, entrecortado, revela la incomunicación, la soledad, la crueldad de las relaciones humanas, el hastío. La ruptura de las reglas del diálogo y de las máximas conversacionales, como la falta de cooperación entre los hablantes, produce réplicas ambiguas, imprecisas, inacabadas. Sin embargo, la imagen, aunque también fragmentaria, alcanza mayor coherencia semántica para traducir y aún anticipar los conflictos. Entre una palabra escindida y una imagen fraccionada se construye esta historia. Las réplicas o parlamentos dan cuenta de la intriga, de la sucesión de los hechos, de su encadenamiento, en un nivel discursivo-narrativo (Pavis, 2001) en tanto las imágenes proyectadas en la pantalla muestran el hacer, la manifestación externa del conflicto, las estructuras actanciales (Pavis, 2001) a través de las acciones físicas. Ellas están detrás de las palabras, revelan el inconsciente del texto e intentan colmar sus lugares de indeterminación. Muestran la incapacidad de los personajes para establecer relaciones interpersonales en una búsqueda desenfrenada que se resuelve en apareamientos casi animales, limitados al contacto de los cuerpos, sin compromiso afectivo alguno. Para Stanislavski (1996: 7) "un pequeño acto físico adquiere un significado interno enorme: la gran lucha interior busca un escape en dicha acción externa...”. El maestro ruso entiende que “las acciones externas adquieren su significado o su calor de los sentimientos internos y éstos encuentran su expresión en términos físicos”. Sanchis Sinisterra (2002: 208-209), por su parte, al considerar la pragmaticidad de la palabra dramática reivindica la afirmación de Stanislasvki -“hablar significa actuar”- y destaca que “decir es hacer”, al observar cómo “todas las corrientes de la pragmática lingüística que se centran en la actividad discursiva nos permiten... analizar objetivamente qué acciones realiza el personaje por medio de su comportamiento verbal: en la propia textualidad de los enunciados se halla inscrita la marca de su facticidad”. 
En Caleidoscopio el “comportamiento verbal” de los personajes tiene su correspondencia en la acción física que la pantalla resalta y destaca en sus mínimos detalles, como se observa en la acotación de la secuencia 3:

(La cámara de Miguel se queda con el rostro de Nieves, deleitándose. Un suave zoom acerca su rostro y recoge hasta el último detalle. Tiene miguitas de pan en los labios, el flequillo rubio sobre los ojos. Levanta la vista y descubre la mirada de la cámara. Finge estar enfadada mientras se acerca)

El conflicto se centra en la dialéctica escenario/pantalla, palabra/imagen que, combinadas, logran la cohesión necesaria para configurar la sintaxis dramática y determinar el estatuto de los personajes. El mecanismo discursivo de la escena, en su complejidad intertextual e intermedial, “teatraliza” el texto pero, a la vez, el comportamiento y vestuario de los personajes es naturalista, real. Ellos se construyen a través de un discurso tortuoso, corrosivo y fraccionado sobre la realidad que viven. Como ocurre en las escrituras dramáticas contemporáneas (Pavis, 2001) no hay aquí contradicción entre teatralidad y naturalismo sino una nueva forma de relación entre el personaje y su discurso, intensificado éste por recurrencias y analogías que, como un eco constante, se continúan escuchando más allá del personaje. En la secuencia 12 la misma acción en pantalla y escenario, se describe en la acotación, como anticipo de un largo monólogo de Nieves ante el mutismo absoluto de Miguel:

\section{PANTALLA/ESCENARIO}

(NIEVES duerme desnuda abrazada a MIGUEL, también desnudo. Se despierta.

Bosteza. Permanece en silencio unos instantes. Luego, acaricia el pelo de Miguel, que abre los ojos lentamente. Nieves los besa. Se incorpora de repente y camina por el escenario. Lleva puestos los calcetines gruesos de vivos colores. La acción que se desarrolla en el escenario también aparece en la PANTALLA, como si Miguel se estuviese grabando a sí mismo y a Nieves, aunque aquél aparecerá sin moverse del 
colchón, mudo, observándola. Quizás encienda algún cigarrillo. El foco de la cámara se acerca o se aleja, encuadra y reencuadra en función de la intensidad del monólogo, tomando también las reacciones de Miguel que se consideren oportunas). Negritas, nuestras.

NIEVES.-

Hay una cosa de mi padre que no te he contado nunca. ¿Te acuerdas del primer día que te llevé a cenar a casa? Pues un momento antes de que llegases mi padre me estaba diciendo -en broma, ya sabes cómo es- que cómo diablos me había podido enamorar de un indio bajito y achaparrado. Te imaginaba como los inmigrantes del documental, ¿sabes? Y decía que no quería tener nietos bajitos y achaparrados... No le dije nada. Cuando llegaste y te vio, me pilló en un aparte y me susurró al oído: si yo fuera tía también me habría enamorado de él. ¿¿Miguel? ¡Miguel! No me estás escuchando. Al menos, podrías fingir que estás dormido.

(Se levanta. Se dirige al lugar donde dijo que estaba la mecedora de la abuela) NIEVES.-

(Finge hablar con la abuela inexistente)

Abuela, ¿qué voy a hacer con él? Casi no habla. No, no es cuestión de timidez. Es así. Callado. Triste. Te mira, te observa. Parece escucharte. Pero nunca sabes si de verdad te escucha. Siempre parece estar en otro sitio. No sé dónde, abuela. Quizás allá, en Perú... Qué sé yo. (Se acerca una mano al oído) ¿Qué? Sí, abuela, yo creo que me ama. No, nunca me lo dice. No. Ya te he dicho que es muy callado. No, abuela, no. Te equivocas. Yo sé que me ama. (A Miguel) ¿Has oído lo que dice mi abuela, Miguel?

MIGUEL.-

...

NIEVES.-

Dice que te deje. 
La pantalla succiona el escenario y concentra en la imagen, la palabra y la acción. El acto verbal y el acto físico, en tanto "verbo-cuerpo”2 operan como síntesis del ideologema dramático. En este caso, el monólogo de Nieves manifiesta la voluntad de mostrar un problema (la incomunicación) que no tiene posibilidad de resolver. El silencio de Miguel es interpretado por Nieves y estimula un cambio en la interpelación, “finge hablar con su abuela”, busca otro destinatario, otro interlocutor, cambia la dirección del discurso apelando a la respuesta. La palabra va siempre en busca del otro, al que se dirige con interrogantes, en un intento por reconstruir algo, por recuperar un cierto orden, pero el silencio se impone y, con él, el vacío.

Se trata de una construcción dramática basada en la poética de la sustracción que tiene en cuenta un "sistema conceptual y estético" (Sanchis Sinisterra, 2002,126) en el que operan, como puntos cardinales de la representación, silencio/oscuridad - vacío/quietud. La ausencia de voz, de luz, de movimiento, de palabras, se convierte en presencia de significados que, aunque fragmentarios y difusos, van construyendo el sentido de la pieza. Es patético en la obra el "silencio de los auditores” (Sanchis Sinisterra, 2002, 126) “que deja a los hablantes perdidos, enajenados, absorbidos por ese espacio vacío, sin nada de qué asirse. Suplicando una respuesta como Nieves, ante el mutismo de Miguel”(Brizuela, 2007):

\section{NIEVES.-}

\section{(Afectada)}

Me haces sentir incómoda, Miguel. Deja de mirarme así. Deja de observarme. Me duele. Siento como si me estuvieras absorbiendo el alma... Como un vampiro. (Continúa mirándola en silencio. Sus ojos en la PANTALLA)

\footnotetext{
${ }^{2}$ Para Pavis $(1994,117)$ el "verbo cuerpo" es “la alianza de la representación de cosa y la representación de palabra... la alianza del texto pronunciado y los gestos (vocales y físicos que acompañan a su enunciación), el vínculo específico que el texto mantiene con el gesto".
} 


\section{NIEVES.-}

Háblame. ¡Dime algo! ¡Lo que sea!

Podríamos trasladar a este texto las funciones que Sanchis $(2002,125)$ aplica a Final de Partida de Beckett, en tanto el mutismo de Miguel “acentúa su papel subsidiario (no secundario) al tiempo que intensifica su carácter impenetrable, su indescifrabilidad”. En la escritura dramática contemporánea el silencio es estructural (Pavis, 2001) porque es anterior al texto, lo absorbe, y la palabra debe luchar contra él "para constituirse, para ir del sonido al sentido". El silencio en el teatro ya no es solamente de orden temático o sicológico sino material, por lo que opera como un soporte no solo de la escritura dramática sino también de la escritura escénica. Sin embargo, sigue siendo el revés de la palabra, su otra cara, y “está ligado al sentido, a la expresión, al subtexto”. El silencio, por otra parte, da tiempo a los espectadores para que completen las figuras, para que atribuyan sentido a cada una de las piezas.

En Caleidoscopio, tras las palabras pronunciadas, emerge la voz de los personajes en un continuo monólogo, producto de esa comunicación conflictiva, de esa interacción perturbada por el silencio del interlocutor. Miguel apenas habla, solo se manifiesta a través de gestos y movimientos. El vacío de la respuesta deja resonando las palabras en el espacio escénico mientras fija la imagen de los hablantes en la pantalla. El interlocutor válido no es Miguel, sino la cámara que registra el discurso, que fija y legitima la palabra y la imagen.

\section{PANTALLA/ESCENARIO}

(Paloma, desnuda, le habla a la cámara mientras recorre el escenario. Está sola. No vemos a Miguel grabando, pero su imagen aparece en pantalla como si lo hiciera.

Paloma no siente ninguna vergüenza ante la cámara. Al contrario, la provoca con miradas y gestos). Negritas, nuestras.

PALOMA.- 
Me gusta cómo tienes decorado esto. (Reflexiona). Mejor dicho: me gusta cómo no lo tienes decorado. Me gusta el vacío de este piso viejo y solemne. Le da un aspecto de plató antiguo, de historia por contar, de principio sin final, qué sé yo. (Se percata de algo en la pared). Pero mira, Miguel: viejas marcas de un mueble en la pared. Una cómoda quizás. O el lujoso tocador donde se desmaquillaba la señora de la casa después de las fiestas. Colocaba las joyas, se cepillaba el pelo... Se metía en la cama, abrazaba desesperadamente la almohada. No podía dormir. Estaba sola. La cama se le hacía una planicie blanca, helada e inmensa: no estaba acostumbrada a meterse en una cama sola. Aquí hay mucho pasado, Miguel. Muchas historias.

(

\section{(...)}

¿Qué piensa la mosquita muerta de que follemos en la casa de su abuela? (Con hiriente ironía) Ah, que no lo sabe... (Sonríe a cámara) ¿Te ha contado el secreto de la familia? No, seguro que no. Es una chica bien educada. Pero debería contártelo. No es justo que vivas en esta casa y que no lo sepas. Yo sé el secreto. ¿Quieres que te lo cuente? No, mejor que no. Debería hacerlo ella. (Pausa. No puede contenerse) Su abuela era puta. Una puta bien instalada. Puede que dejara de ser puta cuando lo conoció a él. Al abuelo de la mosquita muerta. Entonces se convirtió en querida, que aquí en España era una forma más decente de ser puta. ¿Te das cuenta, Miguel, de que el padre de la mosquita muerta es literalmente un hijo de puta y no solamente porque sea nuestro jefe? (Pausa)

La interpelación de Paloma comienza con un tono amistoso, cordial, y termina con la revelación de un secreto de familia, en un discurso donde se manifiesta la manipulación por el saber (Greimas, 1979, 252) en un juego de seducción y provocación, nuevamente ineficaz como recurso para recuperar al otro, para provocar el diálogo. La pantalla absorbe la palabra y se convierte en un signo de grado compuesto (Kowzan, 1992,195) de la escena, en el que convergen todos los significantes verbales y paraverbales para producir sentido.

La pantalla es la escena exterior e interior de los personajes. El proceso de ficcionalización (Pavis, 1994) ya de por sí complejo en el teatro por su doble dimensión textual y escénica, aquí se intermedializa a través de la pantalla que se constituye en centro del discurso teatral. Es en la pantalla, y solamente en ella, donde se manifiesta el intertexto con Antígona de Sófocles (secuencias 8, 14 y 24) 
que revela el conflicto central. Como Antígona vs Ismene, Lúa lucha por enterrar a este nuevo Polinices, no hermano sino amante infiel, en un acto que le permitirá reencontrarse con sí misma y recuperar su perdida identidad. Las tres escenas, en marcada relación anafórica, intra y extrarreferencial, se ubican en el comienzo, a la mitad y hacia el final de la obra, a la que sostienen como un eje narrativo (Serpieri, 1977, 106-109) que organiza el complejo entramado dramático que solo desde ellas es posible leer.

En la secuencia 8 la acotación presenta a Lúa/Antígona/Ismene en la pantalla:

\section{PANTALLA}

(LÚA parece vestida con una especie de túnica improvisada que deja al descubierto uno de sus pechos. Su rostro aparece teatralmente maquillado en dos mitades, una de ellas más oscura. Ojos, cejas, labios, simétrica, claramente divididos. La mitad más oscura de la cara corresponde a ANTÍGONA. La otra, la de tonos más claros, a ISMENE. Se mueve en el cuadro mientras declama delante de la ventana. Siente y vive como Antígona e Ismene, las dos fundidas en un solo cuerpo, inseparables, como dos hermanas siamesas). Negritas, nuestras.

Con su voz, Lúa recupera el diálogo de Antígona e Ismene, ésta paralizada porque “Escuché la amenaza de Creonte”, aquélla, decidida a dar sepultura a su hermano porque “ ¡Y yo escucho la voz del cadáver de Polinices!”. Ismene firme en el cumplimiento de la ley ("Te has vuelto loca, Antígona. Creonte lo prohíbe con la muerte”) y Antígona firme también en su decisión de incumplirla: “¿La muerte! ¿Acaso no es la muerte vivir así humilladas? Se me clavan en el pecho los pelados huesos de mi hermano insepulto. ¡Como espadas!”.

La secuencia 14 presenta a Ismene ofrendando su anillo a los dioses para que le den una respuesta, en tanto Antígona, segura en su decisión, la compadece: “ ¡Pobre Ismene! Los dioses no suben los caminos empinados: ayudan al mortal que los emprende”.

La secuencia 24 muestra nuevamente a Lúa "en su doble papel de Antígona e Ismene”... "Sus movimientos se hacen más violentos a medida que avanza la acción”. En el diálogo entre las hermanas, Ismene trata de impedirla, “¡No irás! 
¡Conmigo está la sensatez!” y Antígona, desafía la autoridad “(Se levanta como impulsada por un resorte).¡Eso mañana los siglos lo dirán! ¡Y los poetas!” Con la preeminencia de la pantalla como signo se produce en la intraescena una compleja red de procesos semiósicos ${ }^{3}$ que se observan en este orden: procesos expresivos como manifestación de contenidos personales y expresión de vivencias individuales, de Lúa, Nieves y Paloma, a través de un discurso marcado por la isotopía de la incertidumbre, en la reiteración y analogía de monólogos que bucean en un mar de dudas, sin otra intención que la de verbalizar sus sentimientos ante un oyente virtual (Miguel) casi siempre en presencia física pero en ausencia dialogal. Este muro de silencio genera un proceso interactivo (el específicamente teatral) no ya entre los sujetos de un diálogo inexistente sino entre los dos ámbitos del conflicto, entre los cuales se produce un diálogo de espacios: espacio real/espacio virtual; escenario/pantalla; palabra/imagen. En consecuencia, la palabra vaciada de significados, incapaz de revelar el sentido, es absorbida por la pantalla que adquiere total autonomía y se constituye en centro de un proceso de significación que deja en virtualidad a emisores (cámara, personajes) y receptores (público) para manifestarse como signo total, como signo de grado X (Kowzan, 1992, 195). El signo pantalla se independiza de los sujetos "y entra en relación de contigüidad, de recurrencia, de contraste, etc. con otros signos, creando, a partir de estas relaciones, nuevos sentidos” (Brizuela, 2000,5). Finalmente, el proceso de interpretación, con un emisor virtual (Miguel, a quien se dirigirá "en los momentos más intensos”,) se produce a través de Lúa, único personaje capaz de leer y leerse en la escena.

Tengo que enterrarte, Miguel, como Antígona a Polinices, aunque después no me espere otra cosa que la espada de Creonte. No quiero ser Ismene, que acepta que tu cadáver se pudra, que los cuervos te saquen los ojos y coman tus entrañas.

(El rostro queda completamente limpio de maquillaje. La piel brilla como los ojos. Se incorpora y se gira hacia Miguel ofreciéndole toda su desnudez)

\footnotetext{
${ }^{3}$ En todo proceso semiósico (Bobes Naves, 1997) se mantiene el esquema básico, emisor-signo-receptor, y, de acuerdo a las posibles relaciones que se establecen entre ellos y al grado de participación de cada uno de esos elementos, se pueden distinguir variantes como Expresión, Significación, Comunicación, Interacción, Interpretación y Transducción. (Brizuela, 2000, 4-12).
} 
Tengo que enterrarte dignamente, Miguel. Tengo que matar a Lúa. Tengo que volver a ser Adriana.

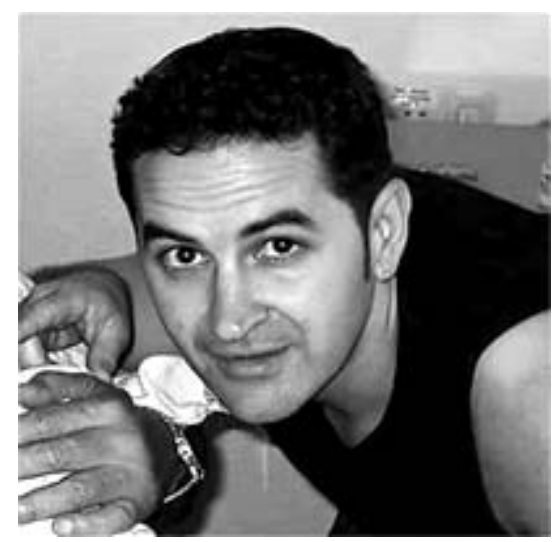

Gustavo Montes

\section{CONCLUSIONES}

Esta secuencia de procesos en una ilimitada cadena de semiosis conforma un mosaico de enunciados que el texto, abierto a la intermedialidad, traslada a su superficie, como los innumerables cristalitos del caleidoscopio (eje anafórico) y el intertexto de Antígona, (eje narrativo/dinámico) entre los cuales se marca, en contraste sutil, la fragilidad de la condición humana a la vez que su capacidad de recuperación a través de un acto de autonomía y libertad individual. El silencio estructural de la obra se transforma en su metáfora y nos remite al ideologema de la incomunicación como unidad textual e ideológica que recorre toda la pieza.

El público no queda fuera de este circuito pero su mirada debe atravesar el escenario para encontrar en la pantalla, el lugar donde se funden la palabra y la imagen.

\section{Bibliografía}

Montes, G. (2006) Caleidoscopio. Original del autor.

Bobes Naves, C. (1997) Semiología de la obra dramática. Madrid, Arco Libros. 
Brizuela, M. (2000) Los procesos semiósicos en el teatro. Análisis de Las meninas y El sueño de la razón de Antonio Buero Vallejo .Kassel, Reichenberger-Universidad de Oviedo.

Brizuela, M. (2007) “Los diez mandamientos del Teatro Hurgente. Una poética de la intensidad”. Ponencia leída en sesión semiplenaria del IX Congreso Argentino de Hispanistas. Mendoza, Facultad de Filosofía y Letras.

González López, G. (2004) “Teatro Hurgente estrena obra y sala”. Nota de Itziar de Francisco en TeatroMundial.com. Online. Febrero.

Greimas. A. y Courtes, J. (1982) Semiótica. Diccionario razonado de la teoría del lenguaje. Madrid, Gredos

Kowzan, T. (1992) Literatura y espectáculo, Madrid, Taurus.

Montes, G. (2005) “Algo así como un prólogo”.Off familia’s (Trilogía de Teatro Hurgente). Hondarribia, Editorial Hiru.

Notas de Prensa (2006) Caleidoscopio. Online. www.janagahteatro.com, 13 de octubre, www.entredosorillas.org, 30 de noviembre.

Pavis, P. (1994) El teatro y su recepción. Semiología, cruce de culturas y posmodernismo. UNEAC, Casa de las Américas, La Habana.

Pavis, P. (2001) Mímeo. Seminario “Las escrituras dramáticas contemporáneas”. Facultad de Filosofía y Humanidades. Universidad Nacional de Córdoba.

Sanchis Sinisterra, J. (2002) La escena sin límites. Fragmentos de un discurso teatral. Valencia, Ñaque. Serpieri, A. (1977) “Ipotesi teorica di segmentazione del testo teatrale”. Strumenti Critici. N No 32-33 Stanislavski, C. (1996) Manual del actor. México, Editorial Diana. 